\title{
Ficções porno-políticas do corpo (a partir) de Preciado
}

\author{
Ana Oliveira' (iD) 0000-0002-5265-0692 \\ 'Universidade de Coimbra, Centro de Estudos Sociais, Coimbra, Portugal. \\ 3000-995-ces@ces.uc.pt
}

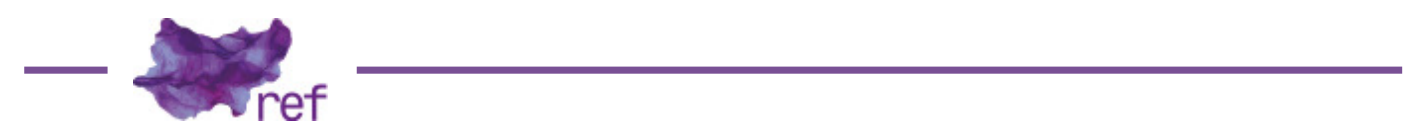

\begin{abstract}
Resumo: Partindo dos escritos de Preciado, este artigo propõe uma problematização contradisciplinar das representações do corpo enquanto produto epistemológico e enquanto laboratório político. A primeira parte, dedicada ao tópico central do Manifesto contrassexual (plasticidade dos sexos e sexos de plástico), discute o sentido de Natureza e a ruptura epistemológica com o discurso sobre uma ordem natural que precede e constitui o humano. A segunda parte centra-se nas noções do corpo como laboratório, introduzidas em Testo yonki. Combinando ficção autopolítica, autoteoria e ensaio corporal, Testo yonki relata um protocolo de intoxicação voluntária à base de testosterona sintética. Essa experimentação corporal, que permite a Preciado ficcionar-se como hacker-sexual ou pirata-dosexo, apresenta-se como um meio de renovação do sentido de si. No seu conjunto, este artigo pretende contribuir para uma análise preciadista de Preciado, isto é, uma análise do sujeito (biografia) que é feita a partir das próprias categorias criadas pelo autor (bibliografia), fazendo de Preciado simultaneamente fonte e objeto de teorização. Trata-se, desse modo, de um ensaio biópico, no qual procuro explorar e combinar as dimensões de produção biográfica e bibliográfica de Preciado.

Palavras-chave: Preciado; sexopolítica; regime farmacopornográfico; ensaio biópico; queer.
\end{abstract}

\section{Preciado's Porno-Political Fictions of the Body}

Abstract: Based on Preciado's writings, this article proposes a counter-disciplinary problematization of body representations as an epistemological product and as a political laboratory. The first part, dedicated to the Counter-sexual Manifesto's core topic (plasticity of the sexes and plastic sexes), discusses the meaning of Nature and the epistemological rupture with the discourse on a natural order that precedes and constitutes the human. The second part focuses on the notions of the body as a laboratory, introduced in Testo junkie. Combining auto-political fiction, auto-theory and body-essay, Testo junkie describes a protocol of voluntary intoxication based on synthetic testosterone. This bodily experimentation, which allows Preciado the fiction of being a sexual-hacker or a sex-pirate, is presented as a means of renewing the sense of the self. Taken as a whole, this article intends to contribute to a preciadian analysis of Preciado, that is to say, an analysis of the subject (biography) made from the very categories created by the author (bibliography), making Preciado simultaneously source and object of theorization. In this sense, this is a biopical essay, in which I try to explore and to combine the biographical and bibliographical dimensions of Preciado.

Keywords: Preciado; Sexpolitics; Farmacopornographic regime; Biopic essay; Queer.

\section{Introdução}

Preciado nasceu em 11 de setembro de 1970, em Burgos, Espanha. Ao nome de família, 'Preciado', foi-lhe acrescentado o prenome 'Beatriz' e atribuído o sexo feminino. Em 1996/1997, ao abrigo de uma bolsa Fulbright, Preciado viaja para Nova lorque para fazer um mestrado em Filosofia e Teoria do Gênero. Em 1999, Jacques Derrida, seu orientador, convida Preciado para ser assistente na Universidade de Paris. É nesse período que Preciado escreve o Manifesto contrassexual. Em 2005, começa a tomar testosterona e, em 2008, publica o livro Testo yonki. Por essa altura, Preciado tinha já regressado aos Estados Unidos para fazer doutorado em Filosofia e 
Teoria da Arquitetura, em Princeton. A sua tese de doutoramento, que seria publicada em 2010, intitula-se Pornotopía: arquitectura e sexualidade en 'Playboy' durante la guerra fria. Desde então, Preciado deu aulas na Universidade de Paris, na Universidade de Nova lorque e em Princeton; dirigiu um programa de estudos do Museu de Arte Contemporânea de Barcelona e tem conduzido a curadoria de vários museus.

Em 2015, Preciado dá-se um novo prenome: Paul. A partir de então, as suas publicações (e traduções) passaram a ser assinadas por Paul B. Preciado.

\section{Sexopolítica}

O Manifesto contrassexual foi publicado originalmente em francês no ano de 2000; em 2002, sai a sua edição em espanhol; a edição portuguesa é publicada no Brasil, em 2014, pela $\mathrm{N}-1$ Edições, e no ano seguinte é publicada em Portugal, pela Edições Unipop. ${ }^{1}$ No prefácio ao Manifesto, Marie-Hélène Bourcier (também autora e teórica das configurações e dos dispositivos da biopolítica e da sexopolítica) afirma que Preciado faz com a filosofia o que o punk ou o rap fizeram com a música. Se o punk se assumiu como a rejeição estética da cena (e da norma) musical, o Manifesto contrassexual de Preciado assumiu-se como rejeição da Natureza (a maiúscula é provocatoriamente deliberada), isto é, como rejeição do discurso sobre uma ordem natural que precede e constitui o humano. E, nesse sentido, como rejeição do discurso biológico sobre a verdade da matéria e dos corpos. Desde logo, como argumenta Preciado, não há células masculinas ou células femininas. 'Feminino' e 'masculino' são conceitos biopolíticos. Invenções adjetivantes. A biologia, portanto, não é mais do que um sistema de codificação no qual já estão implicados processos de interpretação e de produção cultural. Um sistema que, gozando do estatuto epistêmico de ciência, funciona produzindo metáforas performativas; produz aquilo que tenta descrever. A meu ver, essa noção, inspirada na produtividade do poder, de Michel Foucault - que descreve o processo a partir do qual o poder produz os seres que pretende governar e regular -, encontra no conceito de sociologia das ausências um interlocutor oportuno. A sociologia das ausências é uma formulação de Boaventura de Sousa Santos (2002) para descrever uma investigação que visa demonstrar que o que não existe é, na verdade, ativamente produzido como tal (uma alternativa não credível ao que existe). A binarização do regime sexo, entre masculino e feminino, é um exemplo particularmente ilustrativo do modo como ativamente se produz o que existe para lá deste binário (que é também um binômio) como inexistente. As duas possibilidades ontológicas oferecidas, e que se resumem à sua versão masculina ou à sua versão feminina (versões opostas e complementares da unicidade que permite a existência), (re)produzem-se -e tão cuidadamente se cumprem - na invenção da inexistência de outras possibilidades; na invenção da sua fatalidade, da sua inescapabilidade. Uma sociologia das ausências procuraria, então, demonstrar que a não existência de outras possibilidades de existência é produzida como uma alternativa não credível às possibilidades de existência que existem. A categoria intersexo, inventada pelas lentes da biologia (Anne FAUSTO-STERLING, 2000), surge aqui como metáfora possível de algo que a ciência tenta descrever. Já as reivindicações legais e sociais em torno do reconhecimento jurídico de uma terceira categoria para a identificação do sexo ${ }^{2}$ partem precisamente da vontade de produzir uma nova possibilidade de existência, materializando a noção de produtividade do poder: o poder (jurídico, científico, em suma, normativo) produz os seres que pretende governar e regular. Ou seja, a partir do momento em que um ser pode ser descrito e prescrito como intersexo, passa a poder ser governado e regulado enquanto tal podem apresentar-se estatísticas sobre a prevalência; indagar-se padrões sobre antecedentes genéticos; estudar-se os percursos de socialização; etc.

De qualquer modo, essa metáfora do intersexo, do modo como tem sido apropriada pela academia, desistiu de disputar a natureza ficcional dos dois sexos, teorizada por Preciado. Pelo contrário, procura inscrever-se como uma terceira alternativa, que, à semelhança da ficção original, parte de uma estética do corpo, uma estética da sexualidade e do sexo, como recorte da genitália. É a estética visual do corpo, com o recorte da genitália, que determina a diferença sexual (ou rastro diferencial do idioma do carno-falogocentrismo) ${ }^{3}$ como verdade anatômica e que codifica o sexo do sujeito. ${ }^{4}$

\footnotetext{
'A tradução da N-1 Edições é de Maria Paula Gurgel Ribeiro; a tradução da Edições Unipop é de Helena Lopes Braga, Pedro Feijó e Daniel Lourenço (com nota introdutória de Pedro Feijó).

${ }^{2}$ A este propósito, veja-se o relatório "Human rights and intersex people", publicado pelo Comissário Europeu para os Direitos Humanos, Nils Muiznieks, disponível em https://rm.coe.int/16806da5d4; ou o documento da European Union Agency for Fundamental Rights (FRA), "The fundamental rights situation of intersex people", disponível em http:// fra.europa.eu/sites/default/files/fra-2015-focus-04-intersex.pdf.

${ }_{3}^{3}$ Conceitos derridianos que coreografam as intervenções de Hélène Cixous e Jacques Derrida em ldiomas da diferença sexual (edição original de 1994, tradução de Fernanda Bernardo, pela Palimage, de 2018).

${ }^{4}$ Do mesmo modo que é essa estética visual do corpo que determina diferenças na regulação da sua exposição, nas piscinas públicas, ou campos desportivos, ou redes sociais. As redes sociais têm recebido particular atenção devido às políticas sobre os conteúdos, nomeadamente no que diz respeito à proibição da exposição de 'mamilos femininos'.
} 
A estabilização científica que determina, valida (e considera relevante) o fato científico de que há sujeitos do sexo feminino e sujeitos do sexo masculino, desde a prescrição, aparentemente descritiva, do é uma menina ou é um menino, pronunciada perante a ecografia de um feto ou no momento do nascimento, é parte do que Preciado chama uma máquina de produção ontológica que funciona mediante a invocação performativa do sujeito como corpo sexuado. A partir da estabilização da produção dessa diferença como relevante, instala-se toda uma parafernália que funciona como condicionalismos a partir dos quais se inscrevem a subjetivação e a cosmovisão. São esses condicionalismos sociais e identitários que a categoria 'gênero' procurou remeter. Um dos primeiros contributos para a noção de gender no campo dos estudos feministas é de Gayle Rubin, antropóloga norte-americana, na publicação de 1975, "The traffic in women: notes on the 'political economy' of sex". Nesse texto, Rubin explora os mecanismos histórico-sociais a partir dos quais o sexo e a heterossexualidade compulsória ${ }^{5}$ têm sido produzidos - consignando às mulheres uma posição secundária nas relações humanas -, ensaiando a formulação do sistema sexo/gênero. A ruptura epistemológica que essa categoria introduziu permitiu sinalizar os condicionalismos que surgem da descrição-prescrição é uma menina ou é um menino e do modo como regulam a subjetivação e a cosmovisão social: das roupas, adereços, brinquedos, decoração, etc., que precedem o próprio nascimento; às atividades incentivadas e desincentivadas; às qualidades elogiadas e repreendidas (da valentia à docilidade) e todas as restantes dimensões de que o ou a leitora estará provavelmente saturada de ouvir falar (eu sei que estou!). Esses foram passos e contributos teóricos importantes: entender que o que determina as diferenças estruturais e comportamentais das pessoas não é a sua genitália, mas o arranjo eficientíssimo dos dispositivos sociais-jurídicos-médicos-culturais que informam as pessoas.

Ainda assim, a invenção de 'gênero' pouco tem feito para denunciar a fraude sexual. Pelo contrário, tem reforçado a natureza da verdade do sexo ou a verdade da natureza do sexo - como se não fosse o sexo tão só uma codificação, o produto de um consenso biomédico-político, um mecanismo de poder que aciona um conjunto de verdades científicas tautológicas. Ou seja, a introdução da categoria 'gênero' procurou uma ruptura com a dimensão biológica, mas não com o discurso biológico, que toma por adquirido (na categoria sexo) quando lhe oferece um contraponto (o gênero). No entanto, o gênero não é algo que se produz para lá do sexo (natural, pré-discursivo), pois o sexo é já um significado cultural; é já uma leitura interpretativa e prescritiva das possibilidades de existência. Em suma, a biologia e a condição do que é biológico, ou natural, ou natureza, ou realidade, são já um produto e uma mediação cultural.

Produto de uma padronização biológica e produtor de uma naturalização social, o sexo é, desde o século XVIII - quem o afirma é Preciado e, antes de Preciado, Foucault (1976, consultada a edição portuguesa de 1998) -, um objeto de poder e de normalização; uma técnica biopolítica que permite o aparecimento das identidades sexuais e da sua regulação (quer a partir do desvio e da sua criminalização, quer a partir da funcionalidade da norma, nomeadamente a partir dos contratos de casamento ou da perfilhação). ${ }^{6}$ Partindo do conceito de biopolítica, no sentido que Ihe é emprestado por Michel Foucault (2006) 7 (porque há outros sentidos), Preciado (2003) propõe o de "sexopolítica", o qual, admite, se constitui como uma das formas dominantes da ação biopolítica no regime capitalista contemporâneo. Desde logo, a sexopolítica não se restringe à regulação das condições da reprodução da vida, ou aos processos biológicos e epidemiológicos que governam a população; na sexopolítica, i) a sexualidade implica a territorialização precisa da boca, da vagina, do ânus; ii) a heterossexualidade não é uma prática sexual, mas um regime político, no qual o corpo hétero é o produto de uma relação estrutural entre a produção da identidade sexual e a divisão do trabalho, a partir da qual os órgãos são definidos pela sua função, nomeadamente reprodutiva ou não; e iii) o sexo (os órgãos sexuais, a capacidade de reprodução, os papéis sexuais nas disciplinas modernas, etc.) é o correlato do capital. Ou seja, a formulação de sexopolítica evidencia o modo como o sexo (os designados órgãos sexuais, as designadas práticas sexuais, os códigos da feminilidade e da masculinidade, as identidades sexuais normais e desviantes) se impõe nos cálculos de poder, quer através dos discursos sobre o

Nesse caso, trata-se de uma estética visual que esvazia os 'mamilos masculinos' de carga sexual ou erótica e que os equipara a um cotovelo ou a um tornozelo, ou a um nariz. Essa proibição tem, aliás, dado origem a várias publicações que desafiam a premissa dessa política: de mamas mastectomizadas, a mamas a amamentar, a mamas pequenas, etc. Esta disputa tem sido um dos objetos centrais da minha investigação: o estatuto e a regulação da sexualidade, quer nas pretensões dos movimentos e pensamento de matriz feminista, quer nas pretensões familialistas e conservadoras, quer na incorporação da sexualidade nos códigos e normas legais - trate-se do código do trabalho, do código penal, de regras disciplinares dentro de empresas, códigos de condutas dentro de universidades ou termos de uso de plataformas digitais.

${ }^{5} \mathrm{E}$ essa ideia de compulsão não é uma exceção no panorama das práticas e representações sociais; pelo contrário, é constituinte da própria ideia de sociedade e exprime-se em múltiplas categorias vivenciais e conceptuais do sujeito (isto é, todas as formas de ser, estar e agir estão sujeitas a regimes - e ilusões - de compulsoriedade).

${ }^{6}$ Foucault (1998) sublinha a centralidade do sexo e da sexualidade nessa moderna arte de governar a vida, através dos dispositivos da histerização do corpo feminino, da pedagogia sexual das crianças, da regulação das condutas de procriação ou da psiquiatrização de prazeres perversos (eixos deste projeto-processo de modernização sexual). 
sexo e das tecnologias de normalização das identidades sexuais (agentes de controlo da vida), quer através da matriz hétero que assegura o lugar estrutural entre a produção do sexo-identidaderelacionalidade e a produção de certos órgãos como órgãos sexuais e reprodutivos. Essa matriz hétero (e eminentemente completiva) serve a produção de capital que, por sua vez, patrocina a emergência do império sexual. Sexo (órgãos sexuais, capacidade de reprodução, papéis sexuais nas disciplinas modernas, etc.) é o correlato do capital; capitalismo sexual é o sexo do capitalismo.

A indústria pornográfica - que não encerra a asserção anterior, apesar do encadeamento do argumento - é, porventura, um dos dispositivos sexopolíticos mais evidentes, uma vez que, enquanto indústria biotecnológica que opera como um dos tentáculos do bio-sexo-poder, normaliza e naturaliza a utilização dos órgãos, a relação dos corpos, a temporalização e a espacialização das relações entre os corpos. Nesse sentido, como argumenta Preciado no seu Manifesto contrassexual, a pornografia propõe pedagogias da sexualidade; não representa a realidade do sexo, mas opera como uma máquina performativa que produz modelos de sexualidade; estabelece uma distinção entre lugares privados e lugares públicos; entre órgãos sexuais e órgãos não sexuais.

\section{Porno-grafias do sexo}

O tema da pornografia é um campo de estudos vasto e extensamente trilhado que tem servido de palco a profundas contendas dentro da literatura de matriz feminista, que se renovam desde as guerras do sexo - epíteto dado ao clima de produção intelectual e artística no contexto norte-americano, durante as décadas de 1970 e 1980. As guerras feministas do sexo (como porventura deveriam ter sido cunhadas), longe de se esgotarem nos tempos idos do milênio passado, ou no contexto norte-americano, ou no tema da pornografia, ocorrem num clima de guerra fria, colonizando e disputando, em territórios outros, a matriz do sexo e o estatuto da sexualidade: opressão, emancipação; pecado, missão; identidade, relacionalidade. É pois entre as várias propostas na corrente antiantipornografia que surge a pornografia como espaço de enunciação: da chamada pornografia feminista (Tristan TAORMINO et al., 2013; Erika LUST, 2011 ), ${ }^{8}$ ao movimento ético/estético pós-pornô (Annie SPRINKLE, 1991)..$^{9}$ Contrariamente à agenda político-econômica que orienta a pornografia feminista (dos modos de produção dos filmes, aos discursos celebratórios do sexo como ferramenta emancipatória), o pós-pornô, enfaticamente paródico e burlesco, é argila para novos conceitos, argumentos e propostas (como a proposta contrassexual de Preciado). Ambas (pornografia feminista e pós-pornô) fluem, cumprem e restauram o contexto somatopolítico da produção tecnopolítica do corpo que, no pós-ll Guerra Mundial, surge atrelado a novas tecnologias do corpo (biotecnologia, engenharia genética, cirurgias, etc.) e da representação (fotografia, cinema, televisão, internet, etc.) que passam a integrar, a mediar e dar sentido à vida quotidiana. A esse novo regime de produção de corpos e de subjetividades sexuais, assente nas tecnologias biomoleculares, digitais e de transmissão de informação em alta velocidade, Preciado designa "farmacopornográfico".

Por oposição à sociedade disciplinar, sistematizada no trabalho de Michel Foucault, na qual as tecnologias de subjetivação regulam o corpo a partir de um aparato ortopédicoarquitetônico (exterior ao corpo), na sociedade farmacopornográfica, as tecnologias tornam-se parte do corpo, constituem-no, assumem a forma de somatécnicas - do grego sôma, 'corpo'. Em Somatechnics: queering the technologisation of bodies, Nikki Sullivan e Samantha Murray (2009) afirmam que o corpo apenas ilusoriamente é pré-tecnológico; a tecnologia nunca precede o sôma. Nesse sentido, a relação corpo-poder é tautológica: a tecnopolítica assume a forma do corpo, o corpo é produto da tecnopolítica. Os dispositivos disciplinares, ortopédico-sexuais e arquitetônicos, são molecularizados em técnicas microinformáticas, técnicas audiovisuais, técnicas farmacológicas: o poder atua através de moléculas introduzidas no sistema imunológico; de neurotransmissores que alteram percepções e comportamento; de hormônios que atuam de forma sistêmica sobre a fome, o sono, a excitação sexual, a agressividade, o humor. Essas tecnologias

\footnotetext{
7 De acordo com os escritos de Michel Foucault (e.g., 2006), biopolítica é o estilo de governo, nos estados modernos, que regula a população através do biopoder, ou seja, através de técnicas de descrição, regulamentação e controlo das populações. Biopolítica é, na sua literalidade, ter poder sobre os corpos e, nesse sentido, uma tecnologia para gerir os sujeitos: do controlo sobre os corpos, através de uma política anatômica do corpo humano, ao controlo sobre as populações, através das instituições disciplinares. O biopoder não é coercivo; pelo contrário, é uma arte de governar a vida, uma tecnologia política materializada nas arquiteturas disciplinadoras (prisões, quartéis, escolas, hospitais, etc.), nos textos científicos, tabelas estatísticas, cálculos demográficos, manuais, recomendações de uso, calendários de regulação reprodutiva e projetos de saúde pública.

${ }^{8}$ Veja-se a coletânea de 2013, organizada por Tristan Taormino, Celine Parreñas Simizu, Constance Penley, The feminist porn book. Na emergência da chamada pornografia feminista, veja-se também o trabalho de Erika Lust (2011), realizadora de filmes pornográficos que tem estado particularmente empenhada em disseminar um discurso público sobre a pornografia feminista.

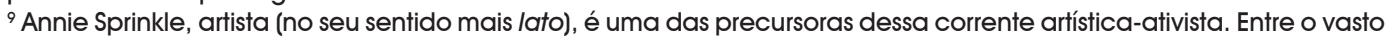
arquivo eletrônico de Annie Sprinkle, veja-se a obra, de 1991, Post porn modernist.
} 
passam a materializar o corpo que regulam, tornam-se inseparáveis e indistinguíveis desse corpo, e é nesse processo que se cumprem como soma-tecno-subjetividades. O corpo já não habita os espaços disciplinadores: está habitado por eles. A estrutura orgânica e biomolecular do corpo é a cela última dos dispositivos biopolíticos de controlo.

Esse é o comando teórico do percurso intelectual de Preciado em Pornotopía: arquitectura e sexualidade en 'Playboy' durante la guerra fria. ${ }^{10}$ A Playboy serve de estudo de caso da ficção teatralizada da sexualidade, cujo mérito e alcance assentavam não na pretensão de transformar as jovens americanas em prostitutas, mas em algo capitalizável e muito mais lucrativo: a Playboy procurava converter tanto os homens como as mulheres em clientes (mais do que em trabalhadores), consumidores da pornotopia sexual Playboy e dos seus produtos derivados. Desse modo, o engenho de Hugh Hefner passou por construir um imaginário capaz de pôr em marcha, em plena guerra fria, os recursos afetivos e axiológicos que permitiriam passar de uma sociedade disciplinar, com as suas rígidas estruturas de governo, a uma sociedade farmacopornográfica, com as suas formas específicas de reprodução da vida: trabalho imaterial, espaço pós-doméstico, regulação psicotrópica da subjetividade, produção sexopolítica, vigilância e consumo da intimidade.

Combinando - como escrevem Michael O'Rourke e Noreen Giffney (2009), no prefácio da antologia organizada por Nikki Sullivan e Samantha Murray - somatecnologias ao serviço de regimes de normalização (como a lei ou a medicina), de regulação de corpos e vidas impróprias, inapropriadas ou inviáveis, com somatecnologias que desestabilizam (queer e crip) a ideia (e ideal) de normalidade e que permitem ao "incoerente ipso-fálico e soberano self" "11 sê-lo, todo um aparato se monta, se renova, se metamorfoseia, de formas extremamente competentes e convincentes, para corresponder às novas formas de consumo sexuais, assentes crescentemente em novas propostas existenciais da sexualidade: a sexualidade-estilo-de-vida, a sexualidadeidentidade-produto, a sexualidade-relacionalidade-consumo. A sexualidade-contrassexual.

\section{O Manifesto contrassexual}

Partindo de uma matriz queer, nas premissas acima sistematizadas, da plasticidade dos sexos à grande fraude sexual, o Manifesto contrassexual procurou, então, desestabilizar a divisão entre órgãos sexuais e órgãos não sexuais, seja através do recurso a sexos de plástico, seja da sexualização dos órgãos não sexualizados.

A contrassexualidade explica-se no confronto com diferentes paradigmas que sustentam, infectam e legitimam o regime sexo ou império sexual: i) o paradigma da Natureza. A contrassexualidade não procura a criação de uma nova natureza, mas o fim da Natureza como ordem que legitima a sujeição de uns corpos a outros; ii) o contrato sociossexual. A contrassexualidade propõe-se como análise crítica das diferenças do sexo, produto de um contrato sociossexual heterocentrado, cujas performatividades normativas são inscritas no corpo como verdades biológicas. Desse modo, o contrato sociossexual é substituído por um contrato contrassexual a partir do qual os corpos não se reconhecem a si mesmos como homens ou mulheres, mas como corpos falantes; iii) o paradigma do saber-poder. ${ }^{12} \mathrm{~A}$ contrassexualidade não é uma luta pela ou contra a proibição (como a que se travava nas guerras do sexo), mas uma contraprodutividade: a produção de formas de prazer-saber alternativas à sexualidade moderna; iv) o paradigma da identidade sexual. Enquanto teoria do corpo, ao reclamar a desconstrução do corpo e da identidade sexual - que não se afigura uma expressão instintiva da verdade prédiscursiva da carne, mas um efeito de reinscrição das práticas do sexo (identidade-relacionalidade) no corpo (logo, corpo = a plataforma de repetição e reiteração) -, a contrassexualidade situa-se fora das oposições binárias homem/mulher, homossexual/heterossexual.

Da plasticidade do sexo que se extrai da compreensão de sexualidade como tecnologia e de sexo como tecnologia biopolítica, o manifesto contrassexual adota o ânus como lugar de desconstrução contrassexual ${ }^{13}$ e o dildo, sexo de plástico, como instrumento contrassexual. Nesse

\footnotetext{
${ }^{10}$ Pornotopía, publicado em 2010, pela Anagrama, e sem edição em Portugal ou no Brasil, traça a história da mansão Playboy e de Hugh Hefner, seu fundador, analisando a emergência de um novo discurso sobre o sexo, a sexualidade, a pornografia, a domesticidade e o espaço público.

${ }^{11}$ No original: "On the one hand there are somatechnologies in the service of regimes of normalisation (such as law or medicine), of the regulation of improper, inappropriate, unviable bodies and lives. On the other, there are somatechnologies which queer (or crip) the idea(l) of normalcy, integrity and which pay attention to the always already tornness and incoherence of the so-called proper, sovereign, ipso-phallic self". (O'ROURKE; GIFFNEY, 2009, p. xii). 12 Veja-se, a esse propósito, Michel Foucault (e.g., 1980, 2002).

${ }^{13} \mathrm{O}$ Manifesto apresenta três características fundamentais que convertem o ânus no centro transitório de um trabalho de desconstrução contrassexual: i) o ânus é um centro erógeno universal, alheio aos limites anatômicos impostos na construção da diferença sexual. Logo, os papéis surgem como universalmente reversíveis. "Quem não tem ânus?", pergunta Preciado; ii) o ânus é uma zona de passividade primordial; um centro de produção de excitação e de prazer que não figura da lista de pontos prescritos como orgásmicos; iii) o ânus constitui um espaço de trabalho tecnológico; é uma fábrica de reelaboração do corpo contrassexual humano. O trabalho do ânus não se destina à reprodução nem se funda no estabelecimento de um nexo romântico; gera benefícios que não podem medir-se dentro de uma economia hétero-centrada.
} 
esquema teórico, a dildotectônica assume-se como a contraciência que estuda a aparição, a formação e a utilização do dildo, e a dildotopia o lugar, ou não lugar, ${ }^{14}$ onde se inverte o eixo semântico e axiológico do sistema heterocentrado. Nesse sentido, o objetivo é aprender a subverter os órgãos sexuais e as suas reações biopolíticas - uma das práticas da dildotopia é a masturbação de um braço (exemplo da desestabilização entre órgãos sexuais e órgãos não sexuais). A ressignificação contrassexual do corpo passaria, em suma, tanto pela ressexualização do ânus e pela utilização generalizada de dildos, quanto pela paródia da simulação orgásmica. ${ }^{15}$

Uma das críticas, antecipadas no Manifesto, denuncia a manutenção da centralidade do falo, representado pelo dildo, na contrassexualidade proposta por Preciado. O grupo das lésbicas feministas antidildo, como as designa Preciado, ou da teoria lésbica separatista que critica a utilização do dildo, pela sua cumplicidade com os signos da dominação masculina, acredita na realidade do pênis como sexo e como um órgão masculino. Segundo Preciado, a erótica hiperfeminizante estrutura o corpo a partir de um esquema corporal monolítico e totalizante e, desse modo, perpetua o sistema falocêntrico que critica. Por oposição, o dildo propõe-se como metáfora; uma metáfora que destabiliza os códigos da masculinidade e da feminilidade não a partir da renúncia ou da indiferença, mas de um protocolo de esvaziamento. Desse modo, o dildo, propõe Preciado, deve ser entendido como uma citação subversiva que parodia os atos entre os corpos; uma falsificação do sexo e uma simulação da carne que testa os limites do corpo e das identidades sexuais; uma prótese que expõe a condição de prótese, ou de incorporação protética, do sexo (identidade-relacionalidade).

\section{Testo yonki: somatecnicizando}

Partindo do conceito de corporalidade e da noção de determinismo biológico e anatômico que dá sentido a essa corporalidade, ou do enclave biopolítico que regula e prescreve o acesso a testosterona, Preciado propõe-se repensar a corporalidade (cela, célula) e a micropolítica das células, invadindo essa fortaleza biopolítica e apoderando-se dela. Um processo somatecnopolítico que se funde ao seu corpo e que produz um novo corpo ou que força o mesmo corpo a produzir uma nova subjetividade, ou cuja falsificação do corpo e da subjetividade forçará Preciado a posicionar-se num contrato social eminentemente sexocêntrico (ou, aliás, diferença-sexual-cêntrico). Tudo começa a ser relatado em Testo yonki. Publicado em 2008, em espanhol, Testo yonki, ou Testo junkie, ${ }^{16}$ apresenta-se como uma autoteoria que relata a experiência de um protocolo de intoxicação voluntária à base de testosterona sintética. Guardada no que designa como "fortaleza biopolítica", Preciado acede à testosterona a partir de um amigo, contornando o sistema da prescrição de testosterona - medicamento sujeito a receita médica, utilizado sob vigilância pericial em casos aprovados para a reatribuição do sexo (ou redesignação sexual) -, e voluntariamente começa a tomar Testogel, um medicamento cuja substância ativa é a testosterona e que é concebido como "tratamento hormonal para homens [com] problemas relacionados com a deficiência em testosterona". ${ }^{17}$ Afirmando-a como ato político e performativo, sobre a qual escreverá entre 2005 e 2006, a aplicação de testosterona prolonga-se por 236 dias e noites. Nesse espaço temporal, Preciado relata as micromudanças fisiológicas e políticas provocadas pela ingestão da testosterona, as transformações bioquímicas da sensibilidade.

Essa experimentação ou ensaio corporal permite a Preciado ensaiar-se como hacker-sexual ou pirata-do-sexo; é um golpe de Estado na medida em que é um golpe ao ser(-se)-sujeito-doEstado; uma ficção autopolítica ou uma autoteoria. É um modo de desfazer o sexo inscrito no corpo (o Undoing gender de Judith Butler, 2004) pela mercadorização e mobilização capitalista sobre a sexualidade e a reprodução. É também um bioterrorismo do sexo à escala molecular que operará num sentido que Preciado porventura não antecipara. E nesse sentido chegou a ser apontado

\footnotetext{
${ }^{14}$ Tratando-se de um conceito teoricamente carregado, cabe aqui uma alusão ao sentido que lhe é atribuído por Marc Augé (2012) pela potencialidade específica do seu uso nesse contexto. De acordo com o autor, se um lugar se pode definir como identitário, relacional e histórico, um espaço que não pode definir-se nem como identitário, nem como relacional, nem como histórico definirá um não lugar. Nesse sentido, a sobremodernidade, por oposição à modernidade baudelairiana, caracteriza-se pela produção de não lugares, que não integram os lugares - repertoriados, ou repertoriáveis, classificados, ou classificáveis, promovidos, ou promovíveis, a "lugares de memória". A dildotopia pode, assim, ser entendida como produto da sobremodernidade.

${ }^{15}$ A par das práticas dildotópicas, o Manifesto apresenta 13 princípios da sociedade contrassexual. Entre os quais o desaparecimento dos registos estatais que identificam as pessoas como sendo do sexo feminino ou masculino; a mudança dos nomes próprios, de forma a escapar às marcas do regime sexo; a abolição dos contratos de casamento e dos direitos de transmissão de patrimônio por herança; ou a absoluta separação entre atividades sexuais e atividades de reprodução.

${ }^{16}$ Traduzido para o inglês por Bruce Benderson e publicado, em 2013, por The Feminist Press, como Testo junkie: sex, drugs, and biopolitics in the pharmacopornographic era. Ainda sem edição em Portugal, no Brasil, a tradução para o português (de Maria Paula Gurgel Ribeiro) é publicada pela N-1 Edições, como Testo junkie: sexo, drogas e biopolítica na era farmacopornográfica.

17 Informação em folheto publicado pela Infarmed, em 2007. Disponível em https://www.bayer.pt/static/documents/ pdf/bhc-ph/Testogel_50_mg_Fl_01-2008.pdf.
} 
como um ponto numa cartografia da extinção. Admitindo, ab initio, que não tomava testosterona para se converter num homem, nem para transexualizar o corpo, este seria um gesto de traição. Seria o seu $V$ for Vendetta. ${ }^{18}$

Não tomo testosterona para me transformar em um homem, nem sequer para transexualizar meu corpo. Tomo simplesmente para frustrar o que a sociedade quis fazer de mim, para escrever, para trepar, para sentir uma forma pós-pornográfica de prazer, acrescentar uma prótese molecular à minha identidade transgênero low-tech feita de dildos, textos e imagens em movimento, para vingar sua morte..$^{19}$ (PRECIADO, 2018b, p. 18).

Projeto e processo de disneyficação, ${ }^{20}$ de mcdonaldização (George RITZER, 1983) ${ }^{21}$ e de playboyzação da materialidade ontológica, a Preciado pode ser reconhecido o atributo que atribuíra a Michael Jackson, o de arquiteto contrapornotópico do próprio corpo. Através de engenharia molecular, Preciado procura uma possibilidade de filosofia, de filosofar(-se); uma possibilidade que exige um corte, talvez o autossacrifício. Já no final de Testo yonki, Preciado recorrendo a uma fábula que lhe havia sido contada por um professor budista jesuíta - afirma que, ao começar esse livro administrando-se testosterona (em vez de discorrendo sobre Hegel, Heidegger, Beauvoir ou Butler), quis decapitar-se, cortar a própria cabeça modelada por um programa cultural de sexo, recortar uma parte do modelo molecular que (a) habitava. Testo yonki seria a pegada deixada por esse corte. Qual seria, por seu lado, a pegada que Testo yonki deixaria em Preciado?

\section{Prometeu pós-moderno}

Em 9 de novembro de 2018, Paul B. Preciado dá uma palestra no Rivoli do Porto, no âmbito do Fórum do Futuro. ${ }^{22}$ Da conceptualização do corpo-objeto, passível de ser modificado, reescrito e recodificado, ao potencial emancipatório de uma reconfiguração-revolução biotecnológica dos corpos subalternos, o corpo que fala à plateia é vulgarmente humano; intuitivamente masculino. A hipotética dissidência, ou renormativização sexual, desse corpo não é pública [é um sexgredo, como refere Hélène Cixous a Jacques Derrida (2018, p. 27)]; tornar-se-á político se assim for mediado discursivamente; como qualquer corpo ou ato. Tento não depositar em Preciado uma confiança sebastiânica no resgaste ontológico; ou, por sucumbir ao formato TEDx Talks, apontar o gigante golpe de marketing em tal culto da personalidade do corpo. As questões que se impõem são de outra ordem: se as células, os fluídos ou os órgãos não são masculinos ou femininos, essa é uma tradução que deles é feita; se a biologia é a linguagem que interpreta e codifica essas células; de que modo e em que termos é que a aplicação de um hormônio (a testosterona), com as consequentes alterações no corpo, força uma alteração na subjetivação? De que maneira essa experimentação reconfigura o corpo dentro ou fora da matriz feminina-masculina? De que modo e em que termos é que expandiu a moldura de representação para o que é (possível ser) humano? De que forma é que as construções e contradições discursivas e epistemológicas, os regimes de produção de identidade, as novas biotecnologias de produção e reprodução do corpo são alheios à possibilidade de os compor? Afirmara Preciado nessa palestra que a vontade de se reconfigurar não precede à experiência, sucede-lhe. É o corpo que dita a subjetividade e não a subjetividade que força a adequação do corpo. É o terrorismo biopolíico sobre as células que modifica o tecido biológico, o organismo, que reclama uma nova interpretação sobre o seu lugar-de-ser. Ou é a nova interpretação do seu lugar-de-ser que reclama a adequação identitária?

A palpável ou ilusória superação de um condicionalismo primário (social, científico, jurídico), que Preciado (2015) argumentara não ser a expressão instintiva da verdade pré-discursiva da carne, mas um efeito da reinscrição das práticas e normas do regime sexo no corpo, encontra nessa experiência molecular um paradoxo irredutível: se a testosterona (enquanto materialidade da carne) não configura, não contém e não presume uma verdade pré-discursiva, é a sua inscrição nos discursos-sobre-si que falseiam esses efeitos; e, nesse sentido, a verdade do sexo é falseável. Se, de outro modo, a testosterona opera na carne, alicerça o corpo e compõe um instinto e uma verdade pré-discursiva, então, a anatomia do sexo é falseável, mas a verdade hormonal, não. Parte do paradoxo assenta na recessão intelectual que resulta desta segunda proposição: o sexo,

\footnotetext{
${ }^{18} \mathrm{~V}$ for Vendetta é um thriller político, distópico, de 2005, realizado por James McTeigue, baseado na banda desenhada com o mesmo nome, escrita por Alan Moore e David Lloyd (DC/Nertigo Comics).

${ }^{19}$ Refere-se a William Baranès, (Guillaume Dustan, de pseudônimo) que morrera de uma intoxicação medicamentosa, não intencional, resultado do uso excessivo de drogas para combater os efeitos colaterais do tratamento do HIV.

${ }^{20}$ Disneyficação como mercadorização de experiências metarreais, no seguimento da tese da transformação do capital em espetáculo, teorizada por Guy Debord em A sociedade do espectáculo (edição original de 1967, traduzida por Franscisco Alves e Afonso Monteiro e publicada pela editora Antígona em 2012).

${ }^{21} \mathrm{Em}$ The 'mcdonaldization' of society, George Ritzer recorre ao termo "mcdonaldização" para reconceptualizar o modelo weberiano (assente na burocracia) da racionalização. A McDonalds representa para o autor o paradigma da racionalidade atual: rápido, homogêneo, acessível.

${ }^{22}$ O Fórum do Futuro é um festival de pensamento que decorre anualmente na cidade do Porto (Portugal). Informações sobre o festival podem ser encontradas em https://www.forumofthefuture.com/.
} 
com todo o seu aparato literário, artístico, médico, jurídico, material (vestuário, arquitetura, consumíveis, etc.), não é senão uma falsificação dos hormônios, da química operada no corpo de que o potencial metafórico da química entre pessoas é herdeiro. E, desse modo, converge no relato autobiográfico de Jan Morris (2017) de o anseio transexual, superando a compulsão social, ser de ordem biológica.

De outra ordem são os episódios de estranhamento, relatados por Preciado, perante a fotografia do seu passaporte, nomeadamente em aeroportos: a fotografia, à qual era reconhecida uma nacionalidade, um nome, um número de identificação civil, fiscal e da segurança social, a fotografia da cidadã Beatriz Preciado não correspondia à imagem da pessoa que transportava aquele documento. ${ }^{23}$ Aquele organismo mutante não existia; era a-legal e, desse modo, corria o risco de ser ilegal. Seria esse reconhecimento legal que Preciado precisaria negociar para existir (nos moldes civilizacionais atuais, usando aeroportos, fazendo compras com cartões de crédito, etc.), nos termos disponíveis: i) reconhecer-se doente, com uma 'disforia de gênero', pedir a alteração do nome e do sexo no registo civil espanhol (ou seja, sujeitar-se às tecnologias de reconhecimento e de produção da identidade e submeter-se às possibilidades de existência do Estado espanhol); ii) rejeitar o corpo que habitava e desfazer(-se d)o seu sexo-prótese masculino.

Um novo cidadão é, assim, registrado no Estado espanhol. Nome: Paul Beatriz Preciado. Sexo: masculino.

\section{O sacrifício de Beatriz}

Na vida e obra de Preciado, Beatriz morre. Teve de morrer. Figurativamente, claro. Mas, o final de Testo yonki resulta quase premonitório; Beatriz é a cabeça decapitada; é o sacrifício para que Paul nasça. A morte figurada de Beatriz por Paul, a criatura inventada por Beatriz Preciado, convoca a história de Victor Frankenstein e da sua criatura, em Frankenstein ou o Prometeu moderno, escrita por Mary Shelley, emprestando potencial metafórico a um quadro analítico que extravasa a experiência biográfica ou política individual: Paul mata Beatriz ou mata a ficção estatal sobre o corpo de Preciado? Ou é a ficção estatal, através da sua disciplina biopolítica, que mata Beatriz? Que a extingue? Do mesmo modo que não deixa nascer tantas outras identidades e só deixa nascer Beatrizes ou Pauls? Uma vez mais, tais interrogações não se circunscrevem a pessoas intersexo, cuja invenção é já produto de uma possibilidade de existência. Uma existência que habita os interstícios de duas possibilidades, mas, ainda assim, a prescrição de um diagnóstico de existência. Refiro-me e debato-me pela existência além-sexo, regime, sistema operativo da diferença-sexual. A feminilidade ou a masculinidade não são meros conceitos, ideologia ou performatividade; são uma ecologia política. A convicção de que se é homem ou de que se é mulher resulta de uma ficção somáticopolítica produzida por um conjunto de tecnologias de domesticação do corpo, de docilização (e agressivização) do corpo, de técnicas farmacológicas e audiovisuais que fixam e delimitam as possibilidades de existência e funcionam como filtros que produzem distorções permanentes da realidade que nos rodeia. O regime sexo é um programa operativo - como o Windows ou o Android ou o iOS - através do qual se produzem percepções sensoriais que tomam a forma de afetos, desejos, ações, crenças, identidades; é um regime que produz um saber interior sobre o 'eu', um sentido sobre o sexual que figura como realidade emocional, evidente, da consciência: sou mulher; sou homem; sou hétero; sou homo; sou bi ou pan ou assexual. Formulações que condensam saberes específicos sobre este astro 'eu' e que atuam como núcleos biopolíticos e simbólicos, memórias RAM, a partir dos quais se aglutinam todo um conjunto de práticas e discursos. Desse modo, não é só a língua que nos usa, tanto quanto nós usamos a língua, parafraseando Robin Lakoff (1973), também o sexo nos usa, tanto quanto nós usamos o sexo.

\section{O sacrifício (do) queer}

Preciado, que poderia continuar a apresentar-se como Beatriz, exercer a (ilusão de) soberania na autonomeação da sua multitude, ${ }^{24}$ opta por apresentar-se como Paul B. Preciado. Na Carta de um homem trans ao antigo regime sexual, Preciado (2018a) afirma que não fala como um homem, nem como uma mulher - uma vez que, voluntariamente e intencionalmente, abandonou essa forma de encarnação política e social; fala como um "homem trans". Não fala como trans, ou anormal, chama a si a convenção de homem e de trans. É daqui que surge o estranhamento sobre a sua ficção de desertor do gênero; a sua ficção de viver cada um dos lados do muro: um muro - o muro do regime hétero-patriarcal, com a sua imposição e rigidez recalcitrante de códigos

\footnotetext{
${ }^{23}$ Na obra autobiográfica Enigma (original de 1974, traduzida e publicada em Portugal, em 1975, pela Iniciativas Editoriais e, em 2017, pela Tinta-da-China), também Jan Morris explora vários episódios e ângulos dessa descoincidência (e da sua antecipação) entre registo civil e reconhecimento social e do desconforto perante o incógnito: do acesso a clubes exclusivos a um dos sexos; às filas dos aeroportos; às distintas formas de tratamento (Mr., Mrs., Miss ou Ms.). ${ }^{24}$ Referência às multitudes queer que dão título ao seu artigo de 2003 , no qual são concebidas como antagonismo dos efeitos normalizadores e disciplinares de toda a formação identitária. Esse artigo é traduzido para português, por Cleiton Zóia Münchow e Viviane Teixeira Silveira, e publicado na Revista Estudos Feministas, em 2011.
} 
e desejos - cuja travessia diária o cansa. 'Trans' é um posicionamento biocultural, sociojurídico, político-pericial na matriz sexo; não a descarta, negocia a sua acomodação nela e, desse modo, confirma a sua verdade, a sua materialidade. Além disso, conceitos como 'mulheres' parecem ter encontrado lugar na cosmovisão de Preciado; do regime de governo à política do desejo, esse sujeito ganha unicidade, perde a sua viscosidade na distância político-biográfica, torna-se operativa de uma responsabilidade/agenda política.

Toda a discussão em torno do pós-modernismo, do pós-estruturalismo, do fim das metanarrativas, de Jean-François Lyotard, que fraturou comunidades intelectuais, e cuja radicalidade foi apontada como paralisante, afigura-se moribunda face ao vigor da economia política (liberal?) da política identitária. Face ao ressuscitar do autor (depois da morte anunciada por Roland Barthes), o autor-de-si, criador-de-si ou biógrafo-de-si que controla o significado-de-si e o projeta numa matriz identitária de um nós; um significado inscrito em experiências de opressão, de sofrimento, de injustiça, escrito nos próprios termos. Um poder-dizer-de-si, identidade sexual, de arquitetar-em-si um happening. É a partir do potencial das metáforas que novas dimensões ecofilosóficas reclamam novas formas de existência - criaturas entre-mundos, pós-sexo, póshumano - e novas formas de hifenização ${ }^{25}$ num mundo crescentemente teorizado, cujas premissas assentam numa combinação aparentemente infinita de opções e combinações estéticas. São essas infinitas opções e combinações estéticas que permitirão, segundo Laura Palazzani (2012), inscrever no corpo, projeto político, a liberdade de expressão de múltiplos, fragmentados, contingentes e individuais desejos e vontades.

Se, por um lado, importa compreender se as metáforas produzem transformação na experiência, descrevem transformações na experiência ou apenas encenam uma transformação que, nesses termos, nem sequer existe, por outro lado, essa disposição do corpo como montra, como hobby, como política e ética de afirmação, converge no sujeito neoliberal, teorizado por Johanna Oksala (2011). A governamentalidade neoliberal, entendida como uma produção particular de subjetividade, produz sujeitos neoliberais, atomísticos, que gerem interesses e fazem escolhas livres com base em cálculos racionais e econômicos; sujeitos cujos hábitos instalados (sujeitos-consumidores $=$ sujeitos-empreendedores) ${ }^{26}$ e interesses convergem, espontaneamente, no interesse de outros sujeitos e que, precisamente por isso, são eminentemente governáveis. As técnicas-conceitos-metáforas da sexualidade revelam-se dispositivos de subjetivação que, simultaneamente, emancipam e capturam os sujeitos nesse investimento-de-si.

É esta, também, a pertinência de Preciado: para lá de uma possível contradição - a de começar por afirmar que não se reconhece mulher, considerar até aberrante essa classificação; ${ }^{27}$ para, em 2018, se reconhecer "homem trans" -, a possível impossibilidade individual de superar dispositivos. Por um lado, como dizer de si quando faltam les mots pour le dire, como escreveu Marie Cardinal (1975)? Como dizer de si e das pessoas quando a língua que falamos nos usa tanto quanto a usamos (LAKOFF, 1973)? Como dizer de si sem ceder à flexão do gênero gramatical? Por outro lado, como dizer-se de si quando os dispositivos linguísticos e estatais que constituem sujeitos exigem essa flexão? Constituem os sujeitos a partir, também, dessa flexão? A condição póshumana é-o na relação com a condição que define o ser humano; é-o quando ser humano é ser um sexo, inescapavelmente - ainda que trans ou inter.

\section{Sujeito-do-seu-autor}

Este tem sido o metaparadoxo nesse campo de estudos: a premissa epistemológica que permitiu questionar a diferença sexual (ou melhor, desconstruir os fundamentos biológicos da diferença sexual que sustentam os fundamentos sociais da diferença sexual), e que, em última instância, se

\footnotetext{
${ }^{25}$ O hífen é o objeto-processo analisado por Jennifer DeVere Brody (1995) na antologia Cruising the performative (organizada por Sue-Ellen Case, Phillip Brett e Susan Foster). Nesse texto, a autora explora o modo como o hífen, lugar gramatical de intersecção, transição, transformação e tradução, marca um espaço performativo de negociação e de acesso a múltiplas identidades; ocupa impossibilidades; localiza e deslocaliza espaços entre estruturas aparentemente binárias e contraditórias. Por sua vez, João Manuel Oliveira (2010) recorre à hifenização como expediente metafórico para o diálogo entre saberes feministas distintos e como proposta teórico-política (de aprofundamento dos espaços hifenizados que com as teorias feministas se foram gerando).

${ }^{26}$ A título ilustrativo pense-se na nova versão do jogo da Hasbro, Monopoly for Millennials: "Esquece as casas. Já sabes que não as vais poder pagar [...]", ir a um festival de música, resgatar um cão, participar de um retiro de ioga ou dormir no sofá de um amigo são algumas das experiências que poderá acumular na nova edição temática do jogo. Ao contrário do clássico - em que os jogadores têm de comprar propriedades -, nessa versão pensada especialmente para os millennials, o objetivo é colecionar experiências e ser o primeiro a criar uma tendência. (Cf. "Monopólio para millennials: 'Esquece as casas, já sabes que não as podes pagar'”, Público, 13 nov. 2018, disponível em https:// www.publico.pt/2018/1 1/13/p3/noticia/monopolio-millennials-1850902). A gramática do devir influencer tem-se mostrado de tal forma rentável que o Papa Francisco a ela tem recorrido, reconhecendo Maria, a gestante de Jesus Cristo, como a primeira influencer (a influencer de deus). (Cf. "Papa pede a jovens para se tornarem nos influencers do século XXI", Lusa, 27 jan. 2019, disponível em https://www.rtp.pt/noticias/mundo/papa-pede-a-jovens-para-setornarem-nos-influencers-do-seculo-xxi_n1 125328).

27 Cf. "Beatriz Preciado en Breve entrevista", Youtube, 2009, disponível em https://www.youtube.com/ watch?v=HfEł5MLUV90.
} 
traduz na impossibilidade de definição de um sujeito político para o qual formular reivindicações legais, é tolhida pela política identitária precisamente pela sua capacidade de oferecer um sujeito político (aliás, vários sujeitos políticos); pela sua capacidade de materializar eixos e expressões de opressão nesse sujeito político; pela sua capacidade de fetichizar o corpo desse sujeito político. Face à morte anunciada da teoria-aplicada queer, o poema do século XVII de John Donne, cuja popularidade provém (creio) do título de Ernest Hemingway que inspirou, For whom the bell tolls, empresta alguma funestação a este meu ponto. Não sendo único, também nesse caso a popularidade da pergunta em muito supera a da sua resposta. For whom the bell tolls ou Por quem os sinos dobram não é sequer, na versão de John Donne, uma pergunta. É um aviso do poeta sobre o que nunca se deve perguntar: "And therefore never send to know for whom the bell tolls". Porque os sinos dobram por ti. O sentido que acompanha essa profecia assenta numa visão holística sobre a humanidade: cada pessoa é uma célula desse corpo que é a humanidade; logo, a morte de uma pessoa é a morte de uma parte desse todo que, por sua vez, afeta inevitavelmente cada parte. Desse modo, os sinos dobram pela humanidade e, como nenhuma pessoa é uma ilha, dobram por $\mathrm{it}^{2{ }^{2} \mathrm{Se}}$ o queer anunciou a morte do feminismo e o feminismo anunciou a morte do queer talvez estejam ambos mortos; talvez a mestria esteja na manipulação orgásmica [cf. "potencial orgásmico", de Preciado (2008)] dos seus espectros, pelo capital. Feminismo ${ }^{\circledR}$. Queer ${ }^{\circledR}$.

As disciplinas biopolíticas (nas quais se inscrevem as guardiãs do lugar de enunciação) continuam a operar como uma máquina ontológica que naturaliza o sexo (logo, a diferença sexual) como metonímia de existência, como regime da natureza. Um exemplo desta natural e naturalizada naturalização da natureza das coisas pode ser encontrado nos termos da densificação jurídica, e da sua latência social, da designada gestação de substituição (ou barrigas de aluguel, na sua formulação mais prosaica). ${ }^{29} \mathrm{Na}$ sua exposição e reivindicação legal, no contexto português, a esse contrato de gestação de substituição só poderiam recorrer mulheres que não tenham útero ou que apresentem lesões que impossibilitem gerar uma gravidez ou em situações clínicas que o justifiquem. ${ }^{30}$ Esse procedimento estaria, assim e desde logo, vedado a outros que não mulheres, uma vez que 0 útero é um órgão feminino e a sua ausência só é traduzível como deficitária em sujeitos mulheres, sujeitos civis mulheres. Ou seja, por um lado, o estatuto civil forja uma superação da linguagem biológica, mas não os termos dessa verdade biológica; dessa realidade que precede a existência. Por outro lado, face à hipótese de extensão do benefício desse 'tratamento' a homens (enquanto pessoas sem útero), são recorrentemente invocados o argumento do patriarcado (exploração do corpo feminino numa cultura masculino-extrativista) e (não de forma irônica) o argumento do contranatura. O acesso a esse método assenta, portanto, na subsidiariedade de uma disposição biológica (ter um útero produtivo) e de uma predestinação social (engravidar).

Se a história dos movimentos político-sexuais recentes é a história da criação de condições de um exercício total de enunciação, ou a história da derrota da força performativa dos discursos, ou de uma reapropriação das tecnologias sexopolíticas de produção existencial, que Preciado (2003) designa de produção dos corpos dos anormais, ou ainda a história da criação de uma possibilidade pós-humana (cf. Donna HARAWAY, 1991; Rosi BRAIDOTTI, 2016), ${ }^{31}$ o que temos assistido é ao recurso estilístico da radicalidade do monstro e do anormal ${ }^{32}$ numa pragmática governamentalizada da razão e do progresso humano. ${ }^{33}$ A paródia e o burlesco são remetidos para festivais de cinema, instalações e performances artísticas, e um neo-beauvoirismo reclama a realidade como fonte de verdade (escrevendo-a).

O-meu-corpo ${ }^{\circledR}$.

\footnotetext{
${ }^{28} \mathrm{Na}$ obra de Ernest Hemingway, essa referência é atribuída ao contexto da guerra civil espanhola, entre 1936-1939, cujo impacto e importância não diria somente respeito ao povo espanhol, mas a todas as pessoas.

${ }^{29}$ No quadro jurídico português, a utilização de técnicas de procriação medicamente assistida (PMA) está regulada na Lei no $32 / 2006$, de 26 de julho. Após as alterações introduzidas pela Lei no $25 / 2016$, de 22 de agosto, o acórdão do Tribunal Constitucional $n^{\circ}$ 225/2018 declarou a inconstitucionalidade de algumas normas previstas na regulação da gestação de substituição. No contexto brasileiro, não há legislação específica em matéria de reprodução humana assistida (RHA). Algumas normas éticas para o uso das técnicas de RHA têm sido publicadas em Resoluções do Conselho Federal de Medicina (CFM). O dispositivo deontológico, atualmente em vigor, é estabelecido na Resolução CFM n 2.121/2015, de 24 de setembro.

${ }^{30}$ Disposição jurídica que regula a procriação medicamente assistida, prevista no artigo $8^{\circ}, n^{\circ} 2$, da Lei $n^{\circ} 32 / 2006$, de 26 de julho, com as alterações introduzidas pela Lei n $25 / 2016$, de 22 de agosto (que regula o acesso à gestação de substituição).

${ }^{31}$ O ciborgue de Haraway (1991) constitui já a metáfora clássica dessa hibridização humano/não humano, orgânico/ inorgânico.

${ }^{32} \mathrm{~A}$ esse propósito, veja-se a cyborg art, nomeadamente o trabalho de Moon Ribas, bailarina, coreógrafa, cyborg, como se apresenta, cujos implantes colocados nos pés, sincronizados com sismógrafos online, lhe permitem sentir os sismos que sacodem o planeta terra. (Cf. "Moon Ribas, a artista cyborg que dança quando sente sismos - e quer salvar a Terra", Público, 30 jan. 2019, disponível em https://www.publico.pt/2019/01/30/p3/perfil/moon-ribas-a-artista-cyborgque-danca-quando-sente-sismos-e-quer-salvar-a-terra-1859424).

${ }^{33}$ Como argumenta Braidotti (2016), a ideia do pós-humano goza de um amplo e crescente prestígio numa era a que se tem procurado dar o nome de "antropoceno", na qual as atividades humanas têm um impacto brutal no ecossistema da terra.
} 


\section{Referências}

AUGÉ, Marc. Não lugares: introdução a uma antropologia da sobremodernidade. Tradução de Miguel Serras Pereira. Lisboa: Letra Livre, 2012.

BRAIDOTTI, Rosi. "Posthuman Critical Theory”. In: BANERJI, Debashish; PARANJAPE, Makarand P. (Orgs.). Critical posthumanism and planetary futures. Nova Deli: Springer India, 2016. p. 13-32.

BRODY, Jennifer De Vere. "Hyphen-Nations". In: CASE, Sue-Ellen; BRETT, Phillip; FOSTER, Susan (Orgs.). Cruising the performative. interventions into the representation of ethnicity, nationality, and sexuality. Bloomington: University of Indiana Press, 1995. p. 149-162.

BUTLER, Judith. Undoing gender. New York: Routledge, 2004.

CARDINAL, Marie. Les Mots pour le dire. Paris: Grasset, 1975.

CIXOUS, Hélène; DERRIDA, Jacques. Idiomas da diferença sexual. Tradução de Fernanda Bernardo. Coimbra: Palimage, 2018.

DEBORD, Guy. A sociedade do espectáculo. Tradução de Franscisco Alves e Afonso Monteiro. Lisboa: Antígona, 2012.

FAUSTO-STERLING, Anne. Sexing the body: gender politics and the construction of sexuality. New York: Basic Books, 2000.

FOUCAULT, Michel. A história da sexualidade l: a vontade de saber. Tradução de Pedro Tamen. Lisboa: Relógio D’Água, 1998.

FOUCAULT, Michel. A verdade e as formas jurídicas. Tradução de Roberto Cabral de Melo Machado e Eduardo Jardim Morais. Rio de Janeiro: NAU Editora, 2002.

FOUCAULT, Michel. É preciso defender a sociedade. Tradução de Carlos Correia Monteiro de Oliveira. Lisboa: Livros do Brasil, 2006.

FOUCAULT, Michel. Power/knowledge: selected interviews and other writings, 1972-1977. New York: Pantheon Books, 1980.

HARAWAY, Donna. Simians, cyborgs, and women: the reinvention of nature. New York: Routledge, 1991.

LAKOFF, Robin. "Language and woman's place”. Language in Society, Cambridge, v. 2, n. 1, p. 4580, abr. 1973.

LUST, Erika. X: a woman's guide to good porn. Maryland: Femme Fatale, 2011.

MORRIS, Jan. Enigma: história de uma mudança de sexo. Tradução de Paulo Faria. Lisboa: Tintada-china, 2017.

OKSALA, Johanna. "The neoliberal subject of feminism". Journal of the British Society for Phenomenology, Abingdon, v. 42, n. 1, p. 104-120, out. 2011.

OLIVEIRA, João Manuel. "Os feminismos habitam espaços hifenizados: a localização e interseccionalidade dos saberes feministas". Ex cequo, Lisboa, n. 22, p. 25-39, 2010.

O'ROURKE, Michael; GIFFNEY, Noreen. "Series editors' preface. originary somatechnicity”. In: SULLIVAN, Nikki; MURRAY, Samantha (Orgs.). Somatechnics: queering the technologisation of bodies. Farnham: Ashgate, 2009. p. xi-xiii.

PALAZZANI, Laura. Gender in Philosophy and Law. New York: Springer, 2012.

PRECIADO, Beatriz. Manifesto contrassexual: práticas subversivas de identidade sexual. Tradução de Maria Paula Gurgel Ribeiro. São Paulo: N-1 Edições, 2014.

PRECIADO, Beatriz. Manifiesto contra-sexual. Madrid: Opera Prima, 2002.

PRECIADO, Beatriz. "Multidões queer: notas para uma política dos 'anormais'". Revista Estudos Feministas, Florianópolis, v. 19, n. 1, p. 11-20, 2011. 
PRECIADO, Beatriz. "Multitudes queer: notes pour une politiques des 'anormaux'". Multitudes, Paris, v. 12, n. 2, p. 17-25, 2003.

PRECIADO, Beatriz. Pornotopía: arquitectura e sexualidade en 'Playboy' durante la guerra fria. Barcelona: Anagrama, 2010.

PRECIADO, Beatriz. Testo yonki. Madrid: Espasa Calpe, 2008.

PRECIADO, Paul B. "Lettre d'un homme trans à l'ancien régime sexuel”, Libération, 15 jan. $2018 \mathrm{a}$. Disponível em https://www.liberation.fr/debats/2018/01/15/lettre-d-un-homme-trans-a-l-ancienregime-sexuel_1622570. Acesso em 01/10/2020.

PRECIADO, Paul B. Manifesto contrassexual. Tradução de Helena Lopes Braga, Pedro Feijó e Daniel Lourenço. Lisboa: Edições Unipop, 2015.

PRECIADO, Paul B. Testo junkie: sexo, drogas e biopolítica na era farmacopornográfica. Tradução de Maria Paula Gurgel Ribeiro. São Paulo: N-1 Edições, 2018b.

RITZER, George. "The 'mcdonaldization' of society". The Journal of the American Culture, v. 6, n. 1, p. 100-107, Spring, 1983.

RUBIN, Gayle. "The traffic in women: notes on the 'political economy' of sex". In: REITER, Rayna R. (Org.). Toward an anthropology of women. New York: Monthly Review Press, 1975. p. 157-210.

SANTOS, Boaventura de Sousa. "Para uma sociologia das ausências e uma sociologia das emergências". Revista Crítica de Ciências Sociais, Coimbra, n. 63, p. 237-280, out. 2002.

SPRINKLE, Annie. Post porn modernist. Amsterdam: Art Unlimited, 1991.

SULLIVAN, Nikki; MURRAY, Samantha (Orgs.). Somatechnics: queering the technologisation of bodies. Farnham: Ashgate, 2009.

TAORMINO, Tristan; SIMIZU, Celine Parreñas; PENLEY, Constance; MILLER-YOUNG, Mireille (Orgs.). The feminist porn book: the politics of producing pleasure. New York: Feminist Press, 2013.

Ana Oliveira (anaoliveira@ces.uc.pt) é socióloga e investigadora no Centro de Estudos Sociais da Universidade de Coimbra. Doutora em Estudos Feministas (2018), pela Faculdade de Letras da Universidade de Coimbra, com a tese intitulada $A$ expressão normativa do assédio: aproximações sociojurídicas à sexualidade.

\section{COMO CITAR ESSE ARTIGO DE ACORDO COM AS NORMAS DA REVISTA}

OLIVEIRA, Ana. "Ficções porno-políticas do corpo (a partir) de Preciado". Revista Estudos Feministas, Florianópolis, v. 28, n. 3, e61544, 2020.

\section{CONTRIBUIÇÃO DE AUTORIA}

Não se aplica.

\section{FINANCIAMENTO}

Não se aplica.

\section{CONSENTIMENTO DE USO DE IMAGEM}

Não se aplica.

APROVAÇÃO DE COMITÊ DE ÉTICA EM PESQUISA

Não se aplica.

\section{CONFLITO DE INTERESSES}

Não se aplica. 


\section{LICENÇA DE USO}

Este artigo está licenciado sob a Licença Creative Commons CC-BY International. Com essa licença você pode compartilhar, adaptar, criar para qualquer fim, desde que atribua a autoria da obra.

\section{HISTÓRICO}

Recebido em 13/02/2019

Reapresentado em 14/10/2019

Aprovado em 13/12/2019 